\title{
'Neutrality', 'Choice', and 'Ownership' in the Construction, Use, and Adaptation of Judicial Decision Support Systems
}

\author{
Cyrus Tata $^{1}$
}

\section{Abstract}

This article examines the character and future of Judicial Decision Support Systems (JDSS's) in relation to the activity of judicial sentencing. There are many varieties of JDSS which could be applied to sentencing. However, in terms of attracting judicial and political commitment 'Sentencing Information Systems' seem to be emerging as the predominant JDSS model. This model stresses values of data neutrality; judicial choice; and, judicial ownership of sentencing practice and sentencing reform. The article proceeds to examine the 'flip side' of each of these values. It discusses the reasons for the apparent neutrality of SIS data arguing that this 'neutrality' is necessarily a construction based in sentencing research. Examining the value of judicial choice in whether or not the system should be consulted, the article presents results of evaluation of the extent and nature of use of the Scottish Sentencing Information System currently being operated by High Court judges. There is some reason to believe that previous Canadian experience may not necessarily be replicated elsewhere, although it is still early in the history of the Scottish project. Finally, the article considers the ability to retain judicial ownership of the system and public access arguing

${ }^{1}$ Lecturer, Centre for Sentencing Research, Law School, University of Strathclyde, Glasgow, G4 ORQ. Tel: UK + (0)141548 3738. Fax: UK + (0)141553 1546. E-mail: Cyrus.Tata@strath.ac.uk. 
that access is inevitable and that there are a variety of ways in which SISs might be developed. The article concludes that although it is tempting to assume that the construction of an SIS is a mainly technical exercise, this is a mistake and that research is indispensable to realising its arguments of genuine neutrality; choice; and, judicial ownership.

\section{Introduction}

This article examines the background, context, history, current and future progress of judicial sentencing decision support systems. It begins with a brief examination of the Scottish system currently being operated in the Scottish High Court and then proceeds to a brief overview of parallel international developments considering the context and judicial interest in such systems. The article then looks critically at some of the key questions which research-developers of such systems are likely to face concluding with a warning against the seductive assumption that the construction and pursuit of Sentencing Information Systems (SISs) is a mainly technical exercise.

\subsection{Background to The Scottish Sentencing Information System}

The Sentencing Information System (SIS) which is now operated by the Scottish High Court has a history which began in the early 1990s. The immediate impetus to examine the feasibility of a judicial sentencing decision support system (JSDSS) came from the second most senior judge in Scotland, The Lord Justice Clerk, who, together with the support of the Lord Justice General, contacted researchers at Strathclyde University. The main objective of the project has been to research, develop, test, and enhance a computerized information system which would provide judges with comprehensive and meaningful information about the sentencing patterns of the High Court. ${ }^{2}$ It was recognized that it was imperative that the system should be quick to use and simple to operate, even by the most technologically inexperienced user. The system enables the sentencer to enter certain information about the case at hand and to display the pattern of previous sentencing by the High and Appeal Courts for cases sharing similar characteristics. Sentencers are thus able to see at a glance what they and

\footnotetext{
${ }^{2}$ There are three criminal courts of first instance in Scotland: the District Court which can only try and sentence cases under Summary procedure and does not sit with a jury; the Sheriff Court which tries and sentences cases under both Summary and Solemn procedure (under solemn procedure cases are tried by a jury); and, the High Court of Justiciary which only tries cases by jury under solemn jurisdiction. Unlike the District and Sheriff Courts, judges of the High Court generally have unlimited powers of sentencing and tries. The Court of Criminal Appeal is also composed of judges from the High Court.
} 
their colleagues have considered to be appropriate sentences for broadly analogous cases. This does not necessarily place any constraints on the sentencing decision of the judge, it merely provides the judge with information which can help the pursuit of consistency.

The system currently contains information on all sentences passed in the High Court over the last seven years. The system is easy and quick to use and very flexible in its operation. The actual operation of the system has been described elesewhere. ${ }^{3}$ So far this data has been collected retrospectively from the full Trial/Case Papers. The most important task of the research project has been to develop meaningful sentencing classifications which could be used to record, store and retrieve information about the offence, the offender. This has been achieved in close consultation with the judiciary. Although the precise thinking behind the system is documented in detail by other publications, ${ }^{4}$ it is important to emphasize that judges were closely involved in the design of the system from the beginning. Decisions about what information should be included in the system and how this information should be classified and presented have been taken in full consultation with the judges through a Judicial Sub-Group ${ }^{5}$; a series of judicial seminars; and, the circulation of documentation. If the system was to be genuinely useful to sentencers then it had to present information in a way that judges found meaningful and which was a reasonable representation of the way in which they felt sentencing was approached in practice. It was also important that judges did not feel that an alien system was being imposed on them, or that the system posed a threat to their independence. To this end it was important that judges felt some sense of 'ownership' of the system.

\subsection{The Emergence of the SIS model of JDSS for Sentencing}

World-wide it is possible to detect an emerging movement towards the use of Judicial Decision Support Systems (JDSS) in the specific model of a Sentencing Information System (SIS) as a method of attempting to achieve consistency. The Scottish system is neither the first nor the last such system.

\footnotetext{
${ }^{3}$ Hutton, N., Tata, C., and Wilson, J. 'Sentencing and Information Technology: Incidental Reform?' International Journal of Law and Information Technology (1995) Vol.2 No.3 255-286; Tata, C. and Hutton, N. 'Scottish Court Develops Sentencing Information System' (December 1997) Overcrowded Times Vol.8 No.6; Hutton, N. Paterson, A. Tata, C., and Wilson, J. A Sentencing Information for the Scottish High Court of Justiciary: Report of the Study of Feasibility (Scottish Office/ HMSO: Edinburgh 1996); Tata, C., Hutton, N., Wilson, J., Paterson, A., and Hughson, I. A Sentencing Information System for the High Court of Justiciary in Scotland: Report of the Study of the First Phase of Implementation and Enhancement (report submitted to the Scottish Courts Administration, Edinburgh 1997), forthcoming.

${ }^{4}$ Hutton, N. Paterson, A. Tata, C., and Wilson, J. A Sentencing Information for the Scottish High Court of Justiciary: Report of the Study of Feasibility (Scottish Office/ HMSO: Edinburgh 1996);

${ }^{5}$ A small group of judges comprised a working group which met regularly with the researchers to conduct much of the preliminary work.
} 
Earlier systems in Canada ${ }^{6}$ and the Australian state of New South Wales ${ }^{7}$ have been developed and institutionalized to varying degrees. As well as the development of experimental systems by teams in the Netherlands ${ }^{8}$ and Israel ${ }^{9}$ there has also been judicial interest in such systems in a number of English-speaking and European countries. ${ }^{10}$

How can this emerging interest and support be explained? Undoubtedly technological advances make the technical development of such systems increasingly viable. However, it is intriguing to observe that the SIS approach has in become the assumed model for a sentencing JDSS judicial and political circles. There are of course, a variety of alternative JDSS models for sentencing, so what are the distinctive characteristics of an SIS model?

An SIS model of sentencing JDSS emphasizes the presentation of aggregate data about normal practice. How that data is used is accepted to be proper matter for judicial discretion. The data is merely offered as a neutral way of informing the decision. The consultation of an SIS is entirely a matter of voluntary choice; its construction is judicially-led and the product 'belongs' to the judges. It would of course be possible to implement a JDSS which did not stress aggregate data but perhaps a single 'correct' decision; which emphasized presumption or even compulsion; and, which was created by some non-judicial body. Indeed, there have been attempts to develop JDSS which stress different values from the SIS model: values of scientific logic, authority, and expertise. ${ }^{11}$ It is also fair to say that almost without exception these systems have received at best limited judicial and political support. This is not to suggest that systems built on this basis are necessarily wrong or inferior, but rather to raise the question of why an SIS model based on aggregate data stressing data neutrality; choice; and judicial ownership has come to be seen as the assumed JDSS model. I will

\footnotetext{
${ }^{6}$ Hogarth, J. (1988) Sentencing Database System: User's Guide, Vancouver, University of British Columbia; Doob, A. and Park, N. (1987): 'Computerised Sentencing Information for Judges: An Aid to the Sentencing Process', Criminal Law Quarterly, 1987 vol. 30 p54.

${ }^{7}$ See the article by Potas et al in this issue; see also, Schmatt, E., (1996) 'Judicial Information Research System (JIRS): A new and integrated approach to the provision of electronic information services for the judiciary', Judicial Officers' Buletin, vol 8 no 7, Sydney, Judicial Commission of New South Wales.

${ }^{8}$ See the article by Van der vinne; Karnekamp; and, van Zwol in this issue.

${ }^{9}$ Schild, U.J. (1995) 'Intelligent Computer Systems for Criminal Sentencing', The Fifth International Conference on Artificial Intelligence and Law: Proceedings of the Conference, Maryland 1995, pp229-238; see also, Schild's article in this issue.

${ }^{10}$ Private communications.

${ }^{11}$ See for example, Lovegrove, A. The Framework of Judicial Sentencing (Cambridge University Press 1997); Lovegrove, A. Judicial Decision Making, Sentencing Policy and Numerical Guidance, (New York: SpringerVerlag 1989; Schild, U. 'Intelligent Computer Systems for Criminal Sentencing', The Fifth International Conference on Artificial Intelligence and Law: Proceedings of the Conference, Maryland 1995, pp229-238; Bainbridge, D. 'CASE: Computer Assisted Sentencing in Magistrates' Courts, Paper presented to the BILETA Conference 1991; Murbach, R. and Nonn, E. 'Sentencing by Artificial Intelligence Tools: Some Possibilities and Limitations' Paper presented at The Joint Meeting of the Law and Society Association and the Research Committee of the Sociology of Law of the International Sociological Association Amsterdam 1991.
} 
return to consider the values of apparent data neutrality; judicial choice; and judicial ownership in practice later. However, in order to understand the movement towards the SIS model stressing judicial choice, I would suggest that it is necessary first to understand the judicial experience of international sentencing reform which provides the main dynamic advancing judicial and political support for the values which the SIS model represents.

\section{The International Experience of Sentencing Reform}

Over the last thirty years increasing concern has been expressed over the degree of disparity in sentencing. ${ }^{12}$ Disparity is said to exist where dissimilar sentences are passed for similar cases and conversely where similar sentences are passed in dissimilar cases. Research world-wide has suggested that some degree of disparity may be normally expected rather than consistency. ${ }^{13}$

Internationally, the response to disparity has tended to be the introduction of 'Guidelines'. ${ }^{14}$ These have taken the form of Sentencing 'Guidelines' which attempt formally to prescribe the range of sentence which judges are required to pass for different kinds of cases.

\subsection{Sentencing 'Guidelines'}

\subsubsection{Numerical 'Guidelines'}

The first approach has been implemented (and controversial) across the USA. Since the 1980's, numerical 'Sentencing 'Guidelines' have been enacted at both federal and state levels. Typically, these 'Guidelines' are based on a Grid which the sentencing judge is required to use to calculate

\footnotetext{
${ }^{12}$ Ashworth, A. 'Towards European Sentencing Standards', European Journal on Criminal Policy and Research (1994) vol. 2 no.1; Frankel, M. Criminal Sentences: Law without Order (Hill \& Wang 1973); Council of Europe 'Recommendation Number R. (92) 17' 1992.

${ }^{13}$ Blumstein, A., Cohen, J. Martin, S., and Tonry, M. (eds) Research on Sentencing: The Search for Reform, 2 vols. (National Academy Press 1983, 1984); Hood, R. Sentencing the Motoring Offender: a Study of Magistrates' Views and Practices (Heinemann: London 1972); Hood, R. in collaboration with Cordovill, G. Race and Sentencing: A study in the Crown Court: A Report for the Commission for Racial Equality (Clarendon Press: Oxford 1992); Hutton, N. and Tata, C. Patterns of Custodial Sentencing in the Sheriff Court, Scottish Office Home and Health Department Central Research Unit: Edinburgh 1995; Tarling, R. Sentencing Practice in Magistrates Courts, Home Office Research Unit, Study No. 56 HMSO: London 1979.

${ }^{14}$ Wasik, M. and Pease, K. (eds) Sentencing Reform: Guidance or Guidelines? (Manchester University Press: Manchester 1987).
} 
'the right' sentence. ${ }^{15}$ Perhaps the best known and best documented 'Guidelines' are the US Sentencing Commissions' Federal 'Guidelines'. These take the form of a grid with offence levels (43 of them) on the vertical axis and criminal history (6 levels) on the horizontal axis. Sentencers plot a point on the grid which corresponds to the seriousness of the offence and the criminal history score of the offender and this gives them a presumptive sentence. If the sentence is a custodial sentence, the 'Guidelines' indicate both the presumptive sentence and the narrow range below and above this point within which sentencers can select a sentence which will not be classed as a departure from the 'Guidelines'. Technically, the 'Guidelines' are presumptive rather than mandatory, that is sentencers should choose a sentence within the prescribed limits, but are allowed to depart from the 'Guidelines' if 'substantial and compelling circumstances' call for a different sentence. The calculation of the appropriate offence level is complex and there is a computer programme, (known as ASSYST), to help probation officers work through the 'Guidelines'. ${ }^{16}$

The Sentencing Commission and its 'Guidelines' have encountered enormous criticism from academics and, judges. ${ }^{17}$ By 1989 over 200 judges had either written judgements or concurred in finding the 'Guidelines' unconstitutional, (although the Supreme Court disagreed with this view).$^{18}$ Many judges have expressed deep concern at the loss of discretion which results in what many perceive to be unjust sentences. ${ }^{19}$

Although the Commission claims that disparity has been reduced, Doob is critical of these claims. The measure of disparity is the extent to which sentencers adhere to the 'Guidelines'. Since sentencers could hardly have been expected to adhere to 'Guidelines' before the 'Guidelines' had been drawn up, it is hardly surprising that disparity defined in this way has been reduced. Similarly, Tonry has noted that a system of 'Guidelines' which are intended to be mandatory in spirit is almost bound to reduce disparity. ${ }^{20}$

\footnotetext{
${ }^{15}$ Frase, R. 'Sentencing Guidelines in Minnesota and other American States: A Progress Report' in Clarkson, C. and Morgan, R. (1995) The Politics of Sentencing Reform, (Oxford University Press 1995).

${ }^{16}$ Simon, E. and Gaes, G. 'ASSYST - Computer Support for Guideline Sentencing', The Second International Conference on Artificial Intelligence and Law: Proceedings of the Conference, Vancouver 1989, pp195-200; Simon, E., Gaes, G., and Rhodes, W. 'ASSYST- The Design and Implementation of Computer Assisted Sentencing’, Federal Probation, 1991, vol 5546.

${ }^{17}$ Alschuler, A. 'The Failure of Sentencing Guidelines: A Plea for Less Aggregation' (1991) University of Chicago Law Review Vol. 58, 901-951; Freed 'Federal Sentencing in the Wake of Guidelines : Unacceptable Limits on the Discretion of Sentencers' 1992 Yale Law Journal, Vol 101, No. 8, 1681-1687; Tonry, M. Sentencing Matters (Oxford University Press 1996); Tonry, M. 'Judges and Sentencing Policy - The American Experience' in Munro and Wasik, M. (eds) Sentencing, Judicial Discretion and Training, (Sweet and Maxwell: London 1992).

${ }^{18}$ Parker, J and Block, M. ‘The Sentencing Commission, P.M. (Post-Mistretta): Sunshine or Sunset?’ 1989 American Criminal Law Review, 27, 289-318.

${ }^{19}$ Doob, A. 'The United States Sentencing Commission Guidelines : If you don't know where you are going, you might not get there' in Clarkson, C. and Morgan, R. The Politics of Sentencing Reform (Oxford University Press 1995)

${ }^{20}$ Tonry, M. 'Judges and Sentencing Policy-The American Experience' in Munro and Wasik (eds) (1992) Sentencing, Judicial Discretion and Training, (Sweet and Maxwell: London 1992).
} 
The question is whether mere adherence to a mechanical system of guidance which has no principled basis is an appropriate measure of uniformity in sentencing. This grid approach can turn justice into a machine in which only very limited formalistic aspects of the case can be considered. Doob argues that there is evidence of considerable disparity in the operation of the 'Guidelines'. Prosecutors and defence lawyers can bargain over the facts of a case as well as over pleas to interpret 'relevant conduct'. This effectively transfers discretion from judges to prosecutors rather than removing discretion. Judges can depart from the 'Guidelines' and take their chances with appeal courts and, as research reported by Doob has noted, probation officers have considerable discretion in the interpretation of 'relevant conduct' to produce the 'correct' offence level. Doob also argues that the differences in the 'Guidelines' between the penal values of different drugs discriminates against black offenders. ${ }^{21}$ Furthermore, there is also evidence that the 'Guidelines' have failed to eliminate gender discrimination in sentencing. ${ }^{22}$

Thus four main criticisms are made of the 'Guidelines'. First, a Sentencing Grid, on which 'Guidelines' have to be based, has been attacked as an artificial way in which to decide sentence. The Grid, on which all Guideline systems have to operate, is said to turn justice into an inflexible machine in which only very limited, formalistic aspects of the case can be considered. Secondly, there is doubt as to whether the implementation of the 'Guidelines' does actually reduce genuine (as opposed to a highly formalistic notion of) disparity. Indeed, recent research suggests that the effect of certain Guideline legislation in the U.S. has been to increase racial disparities in sentencing rather than to decrease them as the original advocates of the Guideline approach had intended. ${ }^{23}$ Thirdly, it is argued that the 'Guidelines' do not eradicate the supposedly pernicious effects of judicial and quasi-judicial discretion. Rather they merely transfer that discretion from the judge to the public prosecutor, (who frames the charge). The prosecutor has to decide how to charge a person and can use the Grid to be able to control the sentencing outcome which s/he desires. Fourthly, there is evidence that 'Guidelines' are routinely 'circumvented' by sentencers, knowledgeable about how the Grid system works, who may be dissatisfied with the ability of the 'Guidelines' to achieve a genuinely just sentence. ${ }^{24}$

It is interesting to note that no jurisdictions outside the United States

\footnotetext{
${ }^{21}$ Doob, A. 'The United States Sentencing Commission Guidelines : If you don't know where you are going, you might not get there' in Clarkson, C. and Morgan, R. The Politics of Sentencing Reform (Oxford University Press 1995).

${ }^{22}$ Nagel, I. and Johnson, B. 'The Role of Gender in a Structured Sentencing System: Equal Treatment, Policy Choices, And the Sentencing of Female Offenders under the United States Sentencing Guidelines', 1994 The Journal of Criminal Law and Criminology Vol 85 No 1, 181-221.

${ }^{23}$ McDonald, D. and Carlson, K. 'Does Race and Ethnicity Matter in Federal District Courts? An Evaluation of the Impact of Federal Sentencing Guidelines on Judicial Sentencing Decisions' Meetings of the Law $\mathcal{E}$ Society Association and Research Committee on the Sociology of Law, Glasgow 1996.

${ }^{24}$ Tonry, M. Sentencing Matters (Oxford University Press 1996).
} 
have used a numerical guideline approach to sentencing reform. Most have preferred an approach which provides Guidelines in a narrative rather than a numerical form.

\subsubsection{Narrative 'Guidelines'}

Other jurisdictions have set up commissions to report on sentencing (e.g. Canada in 1987, Australia in 1988, Ireland in 1996). In Australia, the Sentencing Commission of the state of Victoria, after a ten year period of research and intensive consultation, produced a report in 1988 which resulted in the Sentencing Act (Vic) 1991. The Act consolidates all sentencing provisions in one piece of legislation, provides general guidance for sentencers on the principles of sentencing, sets out aggravating and mitigating factors, describes the means of assessing the seriousness of offences, authorizes the handing down of guideline judgements and lists a clear hierarchy of sanctions. ${ }^{25}$

Sweden passed a Sentencing Act in 1988 based on the 'Desert' principle ${ }^{26}$ which also offers narrative guidance to sentencers. The Act is complex but in essence it provides a detailed set of rules which enable a 'penal value' (non-numerical) to be calculated for each offence. ${ }^{27}$ As in the Victorian legislation, the Act essentially codified existing practice and this perhaps limited potential opposition from the judiciary.

In similar legislation in England and Wales, (the Criminal Justice Act 1991), there was no explicit statement of the principles of sentencing in the Act, a close reading of the Act reveals that the Act intends that 'Desert' should be the primary rationale in sentencing. In effect this means that greater attention is to be paid to the seriousness of the offence and less attention paid to the characteristics of the offender including previous convictions. ${ }^{28}$ The Act requires sentencers to select penalties commensurate with the seriousness of the offence but gives no guidance to sentencers on how to calculate this. ${ }^{29}$ The Act was severely criticized by judges and magistrates including the Lord Chief Justice ${ }^{30}$ and also received considerable negative publicity in the press. While the principle that sentencers should

\footnotetext{
${ }^{25}$ Freiberg, A. Sentencing Reform in Victoria: A Case Study in Clarkson, C., and Morgan, R. The Politics of Sentencing Reform (Oxford University Press 1995).

${ }^{26}$ The Desert principles maintains that sentencing should be primarily (if not exclusively) proportionate to the harm and culpability of the offence actually committed, as opposed to being based for example, on the individual 'needs' of the offender; or, the offender's expected future conduct. See von Hirsch, A. Censure and Sanctions (Clarendon Press 1993).

${ }^{27}$ Jareborg, N. 'Swedish Sentencing Reform', in Clarkson, C. and Morgan, R. The Politics of Sentencing Reform (Oxford University Press 1995); Jareborg, N. 'The Sweedish Sentencing Law', 'European Journal on Criminal Policy and Research'1994 Vol 2, No. 1.

${ }^{28}$ Thomas, D. 'Sentencing Reform: England and Wales' in Clarkson, C. and Morgan, R., The Politics of Sentencing Reform (Clarendon 1995).

${ }^{29}$ Tata, C. 'Conceptions and Representations of the Sentencing Decision Process' Journal of Law E Society 1997 Vol. 24 No. 3.

${ }^{30}$ Taylor, L.J. 'Judges and Sentencing', Journal of the Law Society of Scotland April 1993, 129-131.
} 
consider 'Desert' the primary rationale in sentencing remains, two of the main provisions which tried to implement this principle, the restraint on the use of previous convictions and the unit fine system have been repealed in the Criminal Justice Act 1993. The future of further sentencing reform in England and Wales is uncertain.

\subsection{The presentation of contrasting values of the SIS JDSS model}

The international experience of Sentencing Guidelines presents three major difficulties manifested at intellectual, practical and political levels. The introduction of legislative Guidelines tends to be preceded by an attempt to rationalize the allegedly chaotic practice of sentencing. This is typically achieved through a programme of extensive consultation led by a sentencing commission. Commissions, by their nature, tend to attempt to provide a reasoned explanation for reform based on philosophically derived first principles. Intellectually, it has proved to be a Herculean task for Commissions to explain why, how, and what ways societies ought to punish judicially. Practically, it has been enormously difficult to implement and operate Guidelines. Questions of seriousness, the offence, offender, culpability, harm, and, how these elements inter-relate have in practice been left for the courts to define with the result that both appeal and first instance sentencers have tended to complain about the tangle in which they can find themselves in trying to apply legislative principles. Politically, Guidelines have tended to encounter enormous resistance. Of course, all change meets with resistance, and may be an indication of growing tension between the judiciary and the Executive and Legislature. However, judicial resistance cannot simply be dismissed in terms of blind judicial conservatism. Legislatively-derived principles attempting to implement radical reform have been genuinely problematic to operate. Indeed as I have argued elsewhere $^{31}$ the attempt to implement philosophically-derived principles of punishment may be inherently impracticable.

It is this background (in terms of intellectual, operational, and political difficulties) which largely explains the emerging movement towards the SIS JDSS model. Earlier in this article I suggested that the SIS model can be best understood not so much in terms of its particular technology but by its concern to stress certain values; in particular: data neutrality; judicial choice; and, judicial ownership of sentencing practice and reform. These values contrast sharply in judicial consciousness with the values stressed by the world-wide programme of reform based on Guidelines.

One crucial reason for judicial support for the SIS model lies in the apparent neutrality of its output data. This is thought to contrast sharply with the data (or results) produced by Guidelines. The implicit objective of Guidelines has been understood by judges to define a single 'right', (or at

\footnotetext{
${ }^{31}$ Tata 1997 supra
} 
least a relatively very narrow range), sentence. On the other hand, the SIS model can claim to promote flexibility through aggregate data about "normal' previous practice. To the judicial eye the SIS model presents aggregate data as 'given' and 'neutral'. SIS data is considered to be neutral since it is only based on previous judicial practice, whereas Guidelines have had to be more explicit about the fact that its sentencing suggestions are 'constructed' from abstract principles involving 'outsiders' such as experts, officials and politicians. SIS data can present itself to judges as neutral because it is simply derived from previous judicial decisions.

While the spirit of Guidelines has appeared, (to varying degrees), to be hostile to judicial discretion regarding it as pernicious, arbitrary, and capricious, the SIS model presents its acceptance of judicial discretion and choice as a virtue. While Guidelines have appeared to attempt to eradicate, or, at least, confine judicial discretion, the SIS model appears to embrace judicial discretion presenting itself as a means of informing and so enhancing it. While consultation of an SIS is a matter of judicial choice; sentencers are compelled to apply Guidelines.

Where Guidelines attempt, through philosophically-derived first principles of punishment, to strive towards one correct sentencing answer, the SIS model presents the meaning of data as inevitably a matter of the judgement of the sentencer. In this way, the SIS model presents itself as not in itself a threat to judicial ownership of sentencing practice and reform: sentencing is still accepted as a primary symbolic property of judicial 'independence'.

Thus, the values which SISs and Guidelines publicly emphasize are radically different from each other even though they share the overarching aim of achieving greater consistency. Given this background it is perhaps not surprising that there has been judicially-led political interest and commitment to an SIS JDSS model which stresses values of flexibility, judgement, choice, neutrality of information. The emerging judicially-led movement towards an SIS model of JDSS's can be attributed to the fact that an SIS is patently quite distinct from Guidelines and, in particular, can be viewed as part of a wider struggle to maintain judicial independence.

\section{Questions facing research-developers in the emerging shift to the SIS model of JDSS : Data Neutrality; Choice, and Ownership}

Having explored the background and context of the emerging movement towards the SIS JDSS model, let us now consider some of the questions which research-developers of such systems must inevitably face. I have attempted to define the SIS model of JDSS's not so much in terms of tech- 
nology, but more in terms of the values which it is able to emphasize and advance. These are: the apparent neutrality of SIS data; judicial discretion (or choice in whether to use and how to use the system); and, judicial control and ownership of the system (and by implication an assertion of ownership of sentencing practice and its reform). In the next section I will discuss questions about the 'flip side' of each of these emphasized values. First, the apparent neutrality of data is a key determinant of the credibility of SISs and I will examine the role (and perils) for research in the production of this 'neutrality'. Secondly, choice in whether and how a sentencer uses the system raises the empirical question of the extent and nature of usage of systems already in use. Thirdly, the emphasis on judicial ownership of SISs raises questions about public access to the SIS and the purposes to which it could be adapted.

\subsection{The Construction of Data 'Neutrality' and Credibility}

I suggested earlier that the data (in terms of both input and output) of the SIS model can appear to be neutral and uncontested whereas Guidelines' data tends to appears to sentencers to be imposed, subjective, and thus struggles for credibility. However, SIS data is not in itself any more neutral or value-free than Guideline data. Of course, no such data can ever hope to be value-free. ${ }^{32}$ The way in which information is selected and represented necessarily ensures that it is in a sense always an artificial construction. However, the reason why SIS information can appear to be more neutral is that it attempts to reconstruct images of sentencing in a familiar way tojudges. It is the ability to construct a system in a way which appears to be common-sensical, intuitive and 'obvious' which, in significant part, ensures its credibility. Without credibility judges, of course, will choose not to use an SIS.

However, credibility cannot be gained simply by taking a mass of criminal data feeding it through a computer. What information is to be retrieved? How should relationships between the information be structured? How should it be presented? These questions are the principle determinants of producing a meaningful and credible system to the judicial eye. This might seem to be an obvious point but it would be tempting to overlook it. For example, it is tempting to first identify ready-made data-sets and then to try to design case similarity around the limitations of those data-sets. In many jurisdictions this involves criminal justice data-sets which are collected and recorded primarily for administrative purposes (frequently by a police agency). Such data-sets tend to be vast and appear to be comprehensive. Unfortunately, however, data collected for administrative purposes tends not to meet the requirements of judges in their search for sentences passed for analogous cases. In particular, sentencers need to be able to retrieve

${ }^{32}$ Hutton, N. 'Sentencing, rationality and computer technology' Journal of Law and Society 1996 22(4) 549-570. 
information about sentencing patterns on the basis of cases similar to that which they have at-hand. Here the crucial issue in terms of similarity is case seriousness. Administrative data is unlikely to be an appropriate source from which to judge case seriousness from the perspective of sentencing. It is, after all, collected for the primary purpose of tracking individuals through the criminal process and for police intelligence gathering and detection of future criminal activity.

Let me provide just one example of the difficulties inherent in using administrative data-sets. Let us consider cases involving relating to multiple convictions. How should such cases should be recorded, classified, and represented in aggregate form? This is a question which has received surprisingly little academic attention. ${ }^{33}$ Administrative data sources typically record the overall sentence passed against what the agency assumes, (sometimes on the basis of administrative convenience rather than any intellectual justification), to be the main offence with other convictions getting easily lost. So, for example, a man may be convicted of six sexual offences (two of 'Rape'; four of 'Sodomy' against children for a total net sentence of twelve years' imprisonment. Administrative data sources have to present this sentence against the 'principal conviction' (say, 'Rape') with other convictions getting lost from view. ${ }^{34}$ An SIS based on administrative data will present such a case (at least at the aggregate level) as a twelve year sentence of imprisonment for Rape but cannot signal to the sentencer that there was in that and other similar cases a whole history of other convictions.

Given the institutionalized nature of such data-collection systems and pressure from officials on research-developers to accept the available data, research-developers may have to struggle maintain control over the collection of information which is meaningful from the perspective of constructing an SIS. The Scottish SIS project has been unusual in being able to maintain control over the collection of its own data in a form which would be meaningful to sentencers. The reasons for this control are partly due to the arguments just presented, and, partly because of the impracticalities of down-loading administrative data into the Scottish system. Furthermore, in contrast with the New South Wales system, (which deals with all courts), the Scottish system contains a relatively small data-set, (over 6,000 sentenced cases passed by the High and Criminal Appeal Courts over seven years). This means that in-depth, customized data collection for the Scottish sys-

${ }^{33}$ Tata 1997 op cit; Walker, M. 'Criminal Justice and Offenders' in Interpreting Crime Statistics, ed. M. Walker (Clarendon Press 1995).

${ }^{34}$ Lovegrove makes a similar related point when discussing the New South Wales SIS. He observes the limitations of the output of that system in terms of multiple convictions. 'The Framework of Judicial Sentencing (Cambridge University Press, 1997, p.24). The reason of course for the limitation of output is not caused by the way in which the Judicial Commission chooses to present the data but rather the form in which the administrative data is collected. 
tem is not particularly more onerous or expensive than using administrative data.

It would be tempting to imagine that the construction of an SIS is mainly a technical matter simply involving the development of appropriate technology. There is a danger that research can become its own victim Paradoxically, as the interface becomes more intuitive tojudges and the data appears more neutral, so the construction of similarity is seen as something which is a 'given'. How SIS data comes to be constructed and presented 'neutrally' to judges is necessarily a product of careful empirical research. The criminal and penal law textbooks provide little help in how to construct working definitions of case similarity for the practical purposes of operating an SIS. How sentencers tend to use experience in processing information about cases and come to an outcome can only be explored through empirical research with sentencers. The paradox is that once such a research process starts to achieve results which are accepted as 'common-sense', intuitive, and 'neutral' which are derived from judicial involvement in research, research itself can start to seem superfluous. The more intuitive and neutral the system appears to judges and officials the more likely it is that there will be a temptation to assume that research plays little role in the production of an SIS, or, simply states 'the obvious'. However, what seems intuitive, neutral, obvious and commonsensical to sentencers is itself necessarily the product of research which teases out how in practice sentencers operate and decide!

\subsection{Voluntary Judicial Choice and Utility}

In the section above on the indispensability of research as the basis to constructing 'neutral' SIS data it was explained that if an SIS is not credible to sentencers then it will simply not be used. However, this does not answer the inverse question: if a system is said to be useful, will it be used by sentencers? After all, it is one thing to support an SIS as an alternative to Guidelines, it is another to actually use the system when one is not compelled to do so. Perhaps the most uncharitable interpretation of the judicial impetus behind the advancement of an SIS is that an SIS is no more than a weapon with which to beat off political interference; and, that there is no interest among judges in actually using an SIS. An alternative expectation might be that judges might support an SIS not just because its values of data neutrality, choice, and ownership are distinct from the values apparently represented by Guidelines, but also because sentencers may genuinely think it can enhance consistency. However, whose sentencing should it inform? A sentencer may feel that it need not inform his/her decision-making since that is already 'appropriate' and 'consistent': it is judges $\mathrm{X}, \mathrm{Y}$, and, Z who need the help! A further hypothesis is that sentencers have little interest in an SIS because they do not need to pay its output any attention. In this regard it is 
informative to consider Doob's Canadian experience of researching and developing an SIS during the 1980s.

Doob has described the slow 'closing out' of his SIS project. He has questioned the assumption that (Canadian) judges '... want to have easily accessible to them knowledge of current sentences being handed down in comparable cases ...' and that judges '... would want to know what 'like cases' were getting. We were wrong ... Judges as a rule do not care to know what sentences other judges are handing out.' ${ }^{\prime 5}$ Doob emphasizes that he does not intend to be critical of judges in this respect, but rather to indicate that sentencers operate within an environment which does not reward attention to 'current practice' as the SIS model assumes.

Essentially, then, Doob has argued that from his experience and also, he implies from a similar fate met by Hogarth's system, judges do not perceive there to be a need for good quality information about 'normal practice'. Since judges cannot be coerced into paying attention to such information systems, then judges do not perceive a 'need' for such information. From this point of view, the fact that it might seem strange that there is so little systematic data about normal sentencing practice is immaterial to the practice of sentencing. To what extent has this Canadian experience of judicial indifference to aggregate data been found in other parts of the world and with the two other systems implemented in New South Wales and Scotland?

To date there has been no systematic evaluation programme of the most enduring SIS which is operated in New South Wales. However, the Scottish project recently completed the first phase of the implementation and enhancement of the High Court system. This involved the monitoring of qualitative and quantitative judicial use. Below I briefly outline some of the results of that evaluation which are more fully documented by a recent report on the first phase of implementation and enhancement of the Scottish SIS. ${ }^{36}$

During the first phase of implementation and enhancement the Scottish SIS was operated by around half the High Court judges. Up to fifteen judges had the system loaded onto their personal portable computers. However, due to retirals and secondments in practice the maximum number at any one time was more like twelve. Judges were divided into two cohorts of up to ten and up to five. This enabled enhancements to be made on an incremental basis. Quantitative data was collected by counting the number of log-ins to the system, and from questionnaire data. Information about the charac-

\footnotetext{
${ }^{35}$ Doob, A. 'Evaluation of a Computerized Sentencing Aid' Select Committee of Experts on Sentencing, European Committee on Crime Problems Council of Europe (Strasbourg 1990). Indeed that judges report that they are more concerned with internal consistency than with inter-judge consistency has been reported by other research studies (Tarling 1979, op cit; Hutton and Tata 1995, op cit).

${ }^{36}$ Tata, C., Hutton, N., Wilson, J., Paterson, A., Hughson, I. A Sentencing Information System for the High Court of Justiciary: Report of the Study of the First Phase of Implementation and Enhancement, submitted to the Scottish Courts Administration 1997. Forthcoming.
} 
ter of use was gained from a questionnaire and from individual and group interviews and discussions, and note-books distributed to participating judges so that they could record their thoughts.

A questionnaire was incorporated into the system. This operated on the basis of the number of times the system was started and the period of time since the last use. The user had some flexibility about when $\mathrm{s} /$ he answered the questionnaire but eventually the system response to the questionnaire became mandatory in order to operate the system. However, it was possible for the judge to enter 'no response' to all or any one of the questions. A mandatory response to the questionnaire is calculated by at least every tenth operation or every 28 days whichever is the sooner. The operation of the questionnaire was driven by a log file written each time the system was started. The results of the questionnaire were written to a separate response file. The questionnaire itself consisted of up to six questions ${ }^{37}$ enquiring about the extent of use; how the system is used; whether the judge wishes to see any changes made to the system; and, if so, what kinds of changes.

\subsubsection{Extent of Use}

All judges reported using the system and this is supported by quantitative data collected. There were two quantitative measures of the extent of use judges have made of the system.

One method was the estimation of judges' patterns of use; the other method made an electronic record of each log-in by each judge and Table 1 shows the total number of log-ins recorded for each of the two cohorts. Time is divide into periods of 28 days over a period of one year.

\begin{tabular}{|l|c|c|c|c|c|c|c|c|c|c|c|c|c|}
\hline & & \multicolumn{10}{|c|}{ Time (in periods of 28 days) } \\
\hline & Total & 1 & 2 & 3 & 4 & 5 & 6 & 7 & 8 & 9 & 10 & 11 & 12 \\
\hline Cohort 1 & 252 & 76 & 23 & 23 & 14 & 25 & 20 & 13 & 10 & 22 & 9 & 9 & 8 \\
\hline Cohort 2 & 129 & \multicolumn{1}{|c|}{ not applicable } & 25 & 24 & 14 & 39 & 14 & 11 \\
\hline
\end{tabular}

Table 1 : Extent of use (as measured by the number of 'log-ins') by both cohorts over time

These figures suggest a fairly extensive, sustained pattern of use of the system over one year. Clearly, there are fluctuations, but these reflect the level of sentencing which judges are required to perform. Unlike their counterparts in the lower courts, High Court judges do not pass sentence

\footnotetext{
${ }^{37}$ The use of 'filters' means that the maximum number of questions a judge can be asked at one time is five (see Appendix C of Tata et al 1997).
} 
on a daily basis. Some trials can continue for many days, weeks, or, even months and then may eventually result in the jury returning a verdict of acquittal. It is also important to know that High Court judges are required to conduct civil work which obviously does not require sentences to be passed. Allied to this is the effect of vacation periods. ${ }^{38}$

One interesting matter of investigation was whether the use of the system would merely be a novelty which would appeal to the judges in the first cohort simply because they were the first ever judges to use the system. Would members of the second cohort be less interested in using the system? As we saw earlier, the size of the first cohort was double that of the second and what is striking is that the total number of log-ins suggest that members of the second cohort were no less interested in using the system.

Related to the question of novelty was whether judges would cease to consult the system over time. The figures in Table 1 do not provide evidence of this. However, the number of log-ins by members of the first cohort peaked during the first month (or 28 day period). This might partly be explained by the use of the system during the induction sessions. However, after this first month the rate of use appears to have stabilized with more minor fluctuations from month to month. All judges have used the system. For the reasons given above, it is not meaningful to calculate an average number of log-ins as this would be based on the erroneous assumption that judges were each doing the same amount of criminal sentencing and at the same time.

\subsubsection{Use Over Time}

In its prior report on a feasibility study which built a prototype system, the research team had hypothesized that judicial use of the system might show a steady and constant decline over time as judges became more familiar with the system and with the patterns of sentencing. ${ }^{39}$ However there was little support for this hypothesis. Judicial use of the system, despite fluctuations, appears to have been broadly stable over time and there was no evidence that use became less frequent.

However, measure of use using a log-in count is also limited in as much as it cannot provide any data about the duration of consultation of the system. Judges were asked to estimate how they tended to have consulted the system over the period since the appearance of the last questionnaire. Table 4 below shows judges' aggregate responses over the final month of their evaluation or after the last ten log-ins whichever occurred sooner.

\footnotetext{
${ }^{38}$ The periods in Table 1 are not consonant : the periods are calculated from the day of delivery to each cohort and thus the periods for each cohort do not refer to precisely the same days.

${ }^{39}$ Hutton, Paterson, Tata, Wilson 1996, op cit.
} 


\begin{tabular}{|l|c|}
\hline Frequently in fairly short periods & 12 \\
\hline Frequently in fairly long periods & 2 \\
\hline Infrequently over fairly short periods & 14 \\
\hline Infrequently over fairly long periods & 4 \\
\hline No response & 12 \\
\hline
\end{tabular}

Table 2 : Estimation of periods of use over 28 days or last ten log-ins

These figures confirm the view relayed during evaluation meetings with judges that they prefer not to have to consult the system for long periods, but rather prefer to be able to use the system as a quick and convenient aid. Sometimes, judges reported that they used the system frequently and infrequently at other times, but there is no clear pattern to this and the pattern of use is related to the nature of the cases a judge has to deal with during the period covered by the questionnaire.

\subsubsection{Purposes for Using the System}

Judges were asked about the purpose(s) for which they use the SIS. Judges could select more than one response. The table below shows the results from the last twenty-eight day period.

\begin{tabular}{|l|c|}
\hline Where I have a sentence in mind which I want to check & 20 \\
\hline To get a general view of the pattern of sentencing for cases & 20 \\
\hline To look at Appeal Court decisions for particular cases & 2 \\
\hline Where I have a particularly unusual or difficult case to sentence & 16 \\
\hline For general interest & 7 \\
\hline No response & 15 \\
\hline
\end{tabular}

Table 3 : Purposes in Using the System

The three main reasons given for consulting the system were: where judges had a sentence to check; where they wanted a general view of the pattern of sentences; and, where they had an unusual or difficult case. Most judges gave more than one reason on each questionnaire. Again the response is likely to be determined by the nature of cases for example, a judge 
may only occasionally be faced with a difficult or unusual case and thus may not record this reason on every questionnaire.

\subsubsection{Changes to the system}

There was an overwhelming desire among respondents to see some kind of change to the system. Once again, judges could select more than one response.

\begin{tabular}{|l|c|}
\hline Faster & 2 \\
\hline Easier to operate & 3 \\
\hline Changes in Offence Categories \& Classifications & 3 \\
\hline Changes in Offence Characteristics & 1 \\
\hline Changes in Offender Characteristics & 4 \\
\hline More information on Appeals & 13 \\
\hline More information on First Instance Sentences & 3 \\
\hline Information on Sentencing Law (e.g. maximum penalties) & 2 \\
\hline No response & 9 \\
\hline Text from judges explaining decisions & 1 \\
\hline No changes needed & 3 \\
\hline
\end{tabular}

Table 4 : Desired Changes

The data shows that judges found the system useful for a number of different purposes. This suggests that the system is sufficiently flexible to meet a range of judicial needs and that this could be considered one of its strengths. All judges requested some changes in the system. The most common request was for more information about first instance sentences (thirteen responses) which may be taken along with the nine requests for text explaining decisions as demonstrating a general desire to know more about the circumstances of the case which led to the choice of sentence. Four responses requested more information on appeals in addition to the subsets of data on appeal decisions which can be viewed. Six responses suggested changes to either offence categories or offender classifications. Three responses requested information on sentencing law. Two responses 
wanted the system to be faster. It is perhaps significant that no judge reported a need for the system to be made 'easier to operate' which was one of the possible changes offered in the questionnaire. However, this is not to say that improvements to the user-interface have not been necessary. What was found is that while the system is physically very easy to operate, on-going induction and support are crucial to the maintenance of confidence in the system. Moreover, it is only through on-going contact and discussion with the judges using the system that misunderstandings in the operation of the system can be identified and prevented by improvement of the interface.

In addition to the questionnaires and the electronic record of log-ins, other more qualitative data about judicial perceptions of the system was also collected. Overall, the response of all the judges was positive. All of the judges reported that they had found the system easy and convenient to operate. All found the system useful and felt that it was valuable source of reliable information about the past sentencing practices of the High Court. There was broad and strong support for the addition of a text feature which would allow judges to write a few lines explaining their decisions. There was considerable discussion about the format of this text but agreed that it would only be useful if it was terse. In addition, judges suggested a number of relatively minor changes to the taxonomy and presentation of the system.

This limited evaluation suggests grounds to reassess cautiously the view that Doob's Canadian experience in which judges had no interest in consulting an SIS would necessarily be replicated elsewhere. However, it should be emphasized here that the sample here and the evaluation reported here was limited and has been undertaken early in the history of the implemented Scottish High Court SIS. In addition, the incremental phasing in of the Scottish system has necessitated lengthy periods when the system and its users receive no support and requests for improvements cannot be realized. It would be surprising if these periods did not lead to a corresponding decline in the level of usage.

\subsection{Judicial Ownership of SISs and Public Access}

Judicial attraction to the SIS model of JDSS is, at least in part, a means of retaining control over sentencing practice and its reform. By constructing and maintaining an informal aid to decision-making, the SIS model provides sentencers with a flexible method of both pursuing consistency according to their terms of case similarity, and, to show publicly that they are doing so. Currently, the Scottish SIS is only available to the High Court judiciary, and, in practice, the New South Wales system has not been made widely available beyond judicial officers. However, sentencing is a matter of continual interest among both the general public and particular professional and interest groups. The ability of judges to retain permanent and exclusive control over the whole system must be doubtful. Which groups 
are most likely to be interested in access to the system and how might this interest be responded to?

\subsubsection{Prosecution and Defence}

The prosecutor's office might find an SIS helpful and there may also be a demand from defence agents and from defence counsel. Lawyers have access to the New South Wales SIS, however this access is limited to a very small number of physical locations which are not particularly convenient for lawyers. Currently, the Judicial Commission of New South Wales (which administers the NSW SIS) is negotiating licensing agreements with members of the profession. There is little published information about how lawyers use the system in New South Wales. However, in the neighbouring jurisdiction of Queensland both defence and prosecution lawyers ${ }^{40}$ have access to their own sentencing databases, but it is important to note that these are relatively crude systems created for and by each of these agencies and thus in no way judicial information systems. Perhaps, this reflects the far more adversarial tradition of sentencing in Queensland in which the judge examines sentencing information produced by both defence and prosecution.

\subsubsection{Media and General Public}

There may also be a wider general public interest in the system and it may be that journalists will seek access to the system in due course. It could be argued that the data contained in an SIS is largely a matter of previous, historical public record and therefore there should be public access to it. However some of the material in the Scottish system is drawn from (arguably) confidential reports provided for the court for example by social workers or psychiatrists. Perhaps more important, however, is the way in which data is constructed: it represents the researched distillation of informal judicial interpretation of, and approach to, sentencing. ${ }^{41}$

Nonetheless, in the long-term it may be difficult for Scottish judges to resist demands for public access. If this is the case then the question moves beyond whether public access should be allowed to how this is achieved. Although the Scottish system is easy to use, it is important that potential users receive adequate training to ensure that they understand the underlying principles of the system. The system has been designed to be flexible and could therefore be used to present information in ways which were misleading or censorious and which could threaten public confidence in both the information system and the justice system. One possible way of

\footnotetext{
${ }^{40}$ Provided respectively by the Legal Aid Office and the office of the Director of Public Prosecution (private communications and visit to these offices by the author, July 1997).

${ }^{41}$ Tata, C. 'The Application of Judicial Intelligence and Rules to Systems Supporting Discretionary Judicial Decision-Making’ Artificial Intelligence $\mathcal{E} \mathcal{F}$ Law: An International Journal 6(1) 1998
} 
addressing this potential problem could be for the courts to use the system pro-actively as an educational tool to provide information about sentencing practice in the High Court. This is discussed below.

\subsubsection{Wider applications of an SIS}

\section{Judicial Training and Study}

The growth of bodies to co-ordinate and encourage continuing judicial education are a parallel movement to the emergence of SISs. Bodies concerned with judicial studies might find an SIS, (possibly with some adaptation), very helpful in providing training, (or at least as a source of information for discussion), for the judiciary on sentencing matters. In addition to providing a general view of the patterns of sentencing in the High Court, the system provides a resource for the design of a variety of sentencing exercises, and, could also be used to focus on sentencing for particular types of case.

\section{Public Information}

The interface in the existing SIS's is designed to provide support for sentencers considering passing sentence in specific cases. However there are many other questions about sentencing which could be answered using the data in the system accessed through other means. For example, it should be possible to discern sentencing trends for particular types of case. An SIS can contain a wealth of information about sentencing practices. Bodies concerned with judicial studies might also consider publishing occasional papers based on research into sentencing practice using the data held in the system. These publications would be of interest to sentencers but also to a wider public. Currently general public information about sentencing comes from news reports which highlight 'newsworthy' sentences, presenting them as either excessively severe or more frequently excessively lenient, usually providing a very particular account of the circumstances of the case. However, in most western jurisdictions there is still very limited statistical information available which is sensitive to the relative seriousness of different kinds of cases. ${ }^{42}$ The dissemination of high-quality information would help to place these 'newsworthy' stories in a more informed context. The system would allow the courts to exercise more control over the way in which information about sentencing was presented to the public and could begin to redress the news reporting which may have contributed to the reduction of public confidence in the courts.

Recent research into public attitudes to punishment in England and

\footnotetext{
${ }^{42}$ Hutton and Tata (1995), op cit
} 
Wales reveals some interesting findings. ${ }^{43}$ The research found, inter alia, that public attitudes are far more complex than is commonly assumed by opinion pollsters and headline writers, and, in some respects, more lenient. It also revealed that there is a deep public dissatisfaction with sentencing. Respondents emerged as highly cynical about the ability and performance of sentencers. However, this is not the end of the story. Confirming the findings of previous studies, ${ }^{44}$ this research found that the punishments suggested by the public tend to concur broadly with the sentences actually passed by the courts for similar kinds of cases. However, respondents tended to be systematically misinformed about sentencing practice, often very substantially overestimating sentencers' leniency. When people were asked what sentences they think that the courts actually do pass in specific cases the responses revealed a view of extreme judicial leniency compared with the sentences actually passed. Yet respondents found a series of Court of Appeal judgements broadly acceptable, and advocated sentences that were often in line with current practice. Respondents also lacked any clear understanding of non-custodial and rehabilitative sentences. The conclusion from this seems to be that public opinion, at least in England and Wales, has been systematically misinformed about sentencing practice and that this might be due partly to the fact that there has been little or no high quality aggregate information to counter this misinformation. Proactive use of an adapted SIS for the purpose promoting informed public debate is option which might be explored.

\section{The Perils of Reproduction and Stagnation}

My point in raising questions of access is two-fold. First, as we have seen, the emerging world-wide interest in SISs is at least partly inspired by the attempt to halt Guidelines. Playing the SIS card to trump the Guidelines card requires some publicity. However, the interest which this generates inevitably emphasizes the question of public access. So the paradox is that a system built with and for judges to retain ownership of sentencing can easily lead to the loss of control of the system if the planning and management of public access is ignored.

Secondly, the kinds of uses which wider access to an SIS can provide serves to illustrate how versatile an SIS can be. Both the New South Wales and the Scottish systems have been demonstrated to a variety of agencies,

\footnotetext{
${ }^{43}$ Hough, M. 'People Talking about Punishment' The Howard Journal of Criminal Justice 1996 vol 35 part 3 , 191-214.

${ }^{44}$ Hough, M. and Moxon, D. 'Dealing with offenders: public opinion and the views of victims', The Howard Journal of Criminal Justice, 1985 24, 160-75; Hough, M., Moxon, D., and Lewis, H. 'Attitudes to Punishment' in Pennington, D. and Lloyd-Bostock, D.S., (eds), The Psychology of Sentencing (Oxford: Centre for Socio-Legal Studies 1987).
} 
officials and judges in other jurisdiction. Of course, those precise system are not entirely relevant to other jurisdictions, courts, agencies etc. This is only partly because criminal and penal law may be different but also because purposes and values may also be quite distinct. However, one picture can tell a thousand words and it is tempting to observe the smooth operation of an implemented SIS and to assume that because a system for one court and purpose works smoothly and easily that the same system can (with the substitution of the appropriate legal phrases) neatly be transplanted to another context. Rather, within the SISJDSS model is the potential for a variety of sub-models. ${ }^{45}$ These do not need to involve the same implicit reasoning, nor the same data resources. For example, it is tempting to believe that almost exactly the same system can be built for, say, the lower courts with a complete data-set as in the Scottish High Court. However, given the vastly larger number of sentences passed by say the Scottish District or Sheriff Courts than by the High Court it may be more practicable to provide targeted information systems about certain kinds of decisions (e.g. marginal custodial-non- custodial sentences). Indeed the attempt to reproduce High Court-style system by trying to collect every case over a certain period is likely to prove to be financially and practically unattractive. This would result in a decision to use administrative data, which as I argued earlier, is necessarily inferior to custom-collected data.

Thus, it must be a seductive idea especially to officials that a similar intellectual SIS design to that of existing systems can simply be planted in another context as a quick fix by simply feeding in modified administrative data-sets. However, this is to get caught in a paradox. The values of data neutrality, judicial choice, and judicial ownership which appeal to sentencers can only be realized through research of the particular context and purpose for which a new system is intended. Apparently 'intuitive', 'obvious', 'neutral', and, 'common-sensical' systems have to be constructed on the basis of research which is actively dedicated to uncovering the purpose and context of that intended system.

This article has argued that it is possible to discern an emerging movement towards the SIS model of JDSS for sentencing. The experience and reputation among judges world-wide of Guidelines makes the SIS model privileging values of data neutrality, judicial choice and ownership attractive to judges and thus officials. Whether and how sentencers will make use (beyond being a tool to head off Guidelines) of such voluntary systems remains an open question. According to a limited evaluation of early use of the Scottish SIS, Doob's Canadian may not necessarily be replicated elsewhere. However, a pre-requisite to actual use is credibility and I have argued that merely regarding the transfer of administrative data inevitably raises

\footnotetext{
${ }^{45}$ See David Tait's article in this issue.
} 
questions of credibility. Credible systems cannot be built as a purely technical exercise, but must rather be seen as the product of research into the sentencing decision process. The potential paradox for research-developers is that the more intuitive the product of research becomes, the more superfluous research can appear to be.

However, although the SIS JDSS model has become and is likely to remain the predominant model, there are other sub-models, which, (while sharing the values of data neutrality, choice and choice, and judicial ownership), can offer alternatives to different contexts. The danger is that the construction of SISs will come to be seen as a simple technical matter repeating itself in a standardized way. When they meet the requirements of their judicial users they are likely to be seen as 'simple', 'common-sensical', and thus their construction is unlikely to be recognized as necessitating research about sentencing, but rather as a mainly technical matter. If such systems are to maintain credibility, have the chance of being used, and be employed for a variety of purposes then it is vital that research-developers continue to think imaginatively about alternatives and resist the understandable expectations of judges, and officials to simply reproduce existing systems. 